\title{
De las sorpresas de enseñar a través de una pantalla
}

Trixia Penélope Roldán Álvarez

\begin{abstract}
Resumen
Éste es un testimonio de una profesora de educación primaria, de una escuela pública de la Ciudad de México, durante la pandemia de la covid-19. En él se narra cómo ha sido el proceso de adaptar la práctica docente presencial a una pantalla, se reconoce el esfuerzo de docentes, estudiantes y familias en este período de educación a distancia obligatoria, y se abordan algunas estrategias educativas exitosas, así como los eventos inesperados que surgieron de éstas.
\end{abstract}

Palabras clave: práctica docente, primaria, estrategias didácticas, emociones.

\section{OF THE SURPRISES OF TEACHING THROUGH A SCREEN}

\begin{abstract}
This text is about the experience of a basic education teacher, from a public school in Mexico City, during the coviD-19 pandemic. It explores the adaptation process from the in-person education to the forced distance modality, it recognizes teachers, students and their families' efforts, and discusses some successful didactic strategies, as well as the unexpected events that derived from them.
\end{abstract}

Keywords: teching practice, elementary school, didactic strategies, emotions. 
"De las sorpresas de enseñar a través de una pantalla"

Trixia Penélope Roldán Álvarez

Vol. 22, Núm. 1, enero-febrero 2021

Revista Digital Universitaria

\section{Trixia Penélope Roldán Álvarez}

roldan.penelope@gmail.com

Profesora de educación primaria desde hace siete años, egresada de la Benemérita Escuela Nacional de Maestros y actual estudiante de la Maestría en Desarrollo y Planeación de la Educación en la UAM-X. Ha ejercido en escuelas públicas de la Ciudad de México y Francia.

Docente interesada en temas de literatura infantil, enseñanza del español como lengua extranjera, artes y formación ciudadana.

$\mathrm{H}$

ace poco más de siete años que he sido profesora y, como tal, he experimentado infinidad de vivencias. Aunque sé que la educación no tendría que adaptar mi práctica docente para que cupiera en una pantalla de celular.

Hace unos meses, cuando empezó este nuevo ciclo escolar, como docente de escuela primaria pública sabía que mis estudiantes no contaban con las mejores oportunidades para sobrellevar este duro período de educación a distancia obligada. Sin embargo, estoy sorprendida por el esfuerzo de todos los involucrados: el esfuerzo de las familias por sostener la comunicación con los docentes, el de los profesores por mantener la cordura durante este proceso, y el de las niñas y los niños al tomar clases a distancia.

Cada escuela está organizándose de manera diferente, por ello, las experiencias son aún más variadas. Por mi parte, he implementado varias estrategias, unas más agotadoras que otras, como la maratónica tarea de tener sesiones individuales con cada uno de mis treinta alumnos, para conocerlos mejor, o la de invitar a las familias a hacer videos e intervenciones en las sesiones virtuales.

También, implementé reuniones virtuales de pequeños grupos, para que los estudiantes se pudieran escuchar entre ellos, pues a través de una pantalla la socialización se ve limitada y el docente puede terminar siendo el centro de las clases, cuando éste debería ser el alumno. Estas sesiones tienen como fin convivir con el otro a partir de una emoción. Como son independientes de las sesiones grupales "obligatorias", en ellas abordamos arte, juego y escucha o lo que vaya surgiendo. 
En una de estas sesiones, decidí trabajar con la emoción sorpresa, aunque en realidad quería enfocarme en tristeza. Sin embargo, sé que trabajar la tristeza es todo un reto y si de manera presencial es complicado controlar el llanto de treinta niños, no quería imaginármelo a distancia.

Así que dejé de lado mis libros tristes, las preguntas difíciles y los recuerdos que provocan llanto, y opté por todo lo que causaba sorpresa. Entre las actividades que organicé estaba el asombrarnos con un objeto de su casa - les informé una semana antes para que prepararan su exposición-. Así fue como de la sorpresa llegamos a la tristeza: una niña preparó la presentación de fotos de sus perritos que habían muerto el año pasado y eso la llevó al llanto. Como saben, éste es contagioso y, de la nada, dos niñas empezaron a llorar. El ambiente se nubló, luego un niño recordó a su perrito muerto, una niña a su tía, otra a su abuelita y así fue como tuve a mis alumnitos llorándoles a sus muertos.

¡Qué complicado esto de la distancia! Apapachar a lo lejos es muy difícil y las videollamadas vienen con límite de tiempo. Al final, terminaron todos muy tristes, pero con su familia cerca para recibir el abrazo que la pandemia nos niega a los profesores. Y, bueno, yo quería sorpresa, ivaya que toda esta situación me sorprendió!

Soy una docente a la que le gusta jugar, cantar, reír y experimentar con sus alumnos, y temía que esto se viera limitado por la enseñanza a través de una pantalla. No obstante, con la pandemia he explotado mi lado creativo, y mis estudiantes siguen jugando, cantando, riendo y hasta llorando a través de la pantalla.

En verdad, no dejo de maravillarme de cuántas cosas pueden hacerse en treinta minutos, del compromiso de las familias, de lo trabajadores que son los estudiantes, de lo enriquecedoras que pueden ser las sesiones y, en general, de cómo todos hemos tenido que adaptarnos a esta nueva normalidad. Sé que parece que algo concluyó en marzo, cuando se nos informó que se suspenderían las clases presenciales, pero la realidad es que ese día comenzó una nueva manera de percibir y de llevar a cabo la práctica docente, una práctica llena de sorpresas.

\section{Cómo CITAR ESTE ARTículo}

* Roldán Álvarez, Trixia Penélope. (2021, enero-febrero). De las sorpresas de enseñar a través de una pantalla. Revista Digital Universitaria (RDU), 22(1). DOI: http://doi.org/10.22201/cuaieed.16076079e.2021.22.1.10 